\title{
Acute Onset of Persistent Tachycardia in a Patient with Duchenne Muscular Dystrophy
}

\author{
Madison Nation, $M D^{\prime}$, Megyn Beyer, DO' , Margaret Ellis, DO, MSPH' ${ }^{\prime}$ Nicholas M. Potisek, MD²* \\ 'Pediatric Residency \\ ${ }^{2}$ Department of Pediatrics, Wake Forest Baptist Medical Center Winston-Salem, NC
}

Article Info

\section{Article Notes}

Received: April 09, 2018

Accepted: May 21, 2018

\section{*Correspondence:}

Dr. Nicholas M. Potisek, MD

Wake Forest Baptist Medical Center, Department of

Pediatrics, Medical Center Blvd, Winston-Salem, NC 27157, 336.716.0527; Fax 336.716.2525,

Email:npotisek@wakehealth.edu

C 2018 Potisek NM. This article is distributed under the terms of the Creative Commons Attribution 4.0 International License.

\section{Case Report}

A 10-year-old wheelchair dependent male with Duchenne Muscular Dystrophy, on chronic corticosteroid therapy, presented with persistent tachycardia. Two days prior to presentation he sustained a non-displaced right tibial metaphyseal fracture after a fall from his wheelchair. Later that same day he developed fever and described his "heart racing." He additionally reported some mild chest tightness and a nonproductive cough. The review of systems was otherwise unremarkable.

On physical examination, his temperature was $38.3^{\circ}$, heart rate 149 beats per minute, respiratory rate 20 breaths per minute, normal blood pressure, oxygen saturation $93 \%$ on room air, and body mass index $40.36 \mathrm{~kg} / \mathrm{m}^{2}$. The patient was sitting comfortably in bed and was well-appearing. The lungs were clear to auscultation and there was no increased work of breathing. Cardiac examination revealed tachycardia without murmurs, gallops or rubs; peripheral pulses and capillary refill were normal. No petechiae or other rashes discovered. There was mild swelling of the right ankle with splint in place. The remainder of the physical examination findings were normal.

Initial evaluation included an electrocardiogram that was remarkable only for sinus tachycardia. A complete blood cell count demonstrated an elevated white blood cell count of $23.2 \times 10 * 3 / \mathrm{uL}$ and a complete metabolic panel was notable for an AST of $301 \mathrm{IU} / \mathrm{L}$ and ALT of $276 \mathrm{IU} / \mathrm{L}$. A chest radiograph was normal. A respiratory viral panel, troponin, brain natriuretic peptide and echocardiogram were normal.

Despite two fluid boluses, the patient remained tachycardic prompting further evaluation. D-dimer returned elevated at 1541 NG/ML fibrinogen equivalent units (FEU) (with FDA approved cutoff for venous thromboembolism exclusion $<500 \mathrm{NG}$ /ML FEU). Computed tomography anigography revealed bilateral diffuse, scattered ground-glass opacities with areas of nodular consolidative opacities in a somewhat gravity-dependent pattern; there were multiple peripheral wedge-shaped arterial-distribution opacities with areas of interlobular septal thickening consistent with infarctions (Figure 1).

\section{Final diagnosis}

Fat embolism syndrome secondary to distal metaphyseal tibial fracture in a patient with Duchenne Muscular Dystrophy. 


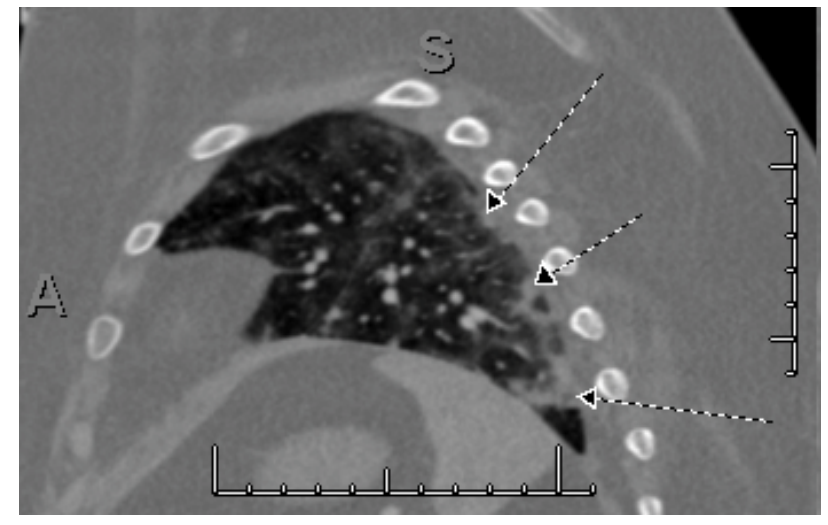

Figure 1. Multiple peripheral wedge-shaped arterial distribution opacities with areas of interlobular septal thickening consistent with infarts (arrows).

\section{Hospital course}

The treatment of pulmonary fat embolism is supportive and our patient received supplemental oxygen and pain medication as needed. Blood culture was negative at 24 hours. The patient's hypoxia and tachycardia improved over 48 hours and he was discharged home with no additional sequelae.

\section{Discussion}

Fat embolism syndrome (FES) is defined as the presence offatglobules in the peripheral circulation resulting in multiorgan dysfunction ${ }^{1}$. FES is primarily a clinical diagnosis with classic presenting symptoms including respiratory distress, neurological alterations and/or a petechial rash ${ }^{2,3}$. Respiratory symptoms range from mild hypoxia to acute respiratory failure. Neurological alterations can include lethargy, confusion, and coma. Additional symptoms may include fever, tachycardia, visual disturbances, and decreased to no urine output ${ }^{1,4}$. Associated laboratory abnormalities include thrombocytopenia, anemia, and/or elevated inflammatory markers ${ }^{1}$. Failure to recognize FES can result in severe complications or even death.

The majority of FES cases result from a recent fracture with the onset of symptoms typically occurs within 72 hours of the injury ${ }^{1,3}$. FES is estimated to occur in 0.3 $1.2 \%$ of patients with isolated fractures of the femur, tibia, or fibula; however, this is likely an underestimate ${ }^{3,4}$. FES is more common in patients 10-39 years of age and occurs rarely in children below the age of 9 years, likely due to the marrow fat differences. Risk of FES varies with the number and location of fractures. Other orthopedic etiologies of FES include bone marrow aspiration/ transplantation, orthopedic procedures, and intravenous lipid administration. Non-traumatic etiologies include osteomyelitis, pancreatitis, sickle cell disease, fatty liver disease, and diabetes mellitus ${ }^{3}$.
Numerous theories exist for the pathophysiology of FES. The mechanical theory suggests fat globules are released into the circulation and obstruct pulmonary or cerebral vasculature resulting in ventilation-perfusion mismatch or cerebral dysfunction ${ }^{1,5}$. The biochemical theory proposes the body generates fatty acids in response to stress causing endothelial and alveolar damage ${ }^{1,5}$. Other theories involve the plasmatic level of lipase or coagulation in physiologic shock $^{6}$. Symptoms are likely related to a combination of these theories.

The diagnosis of fat embolism syndrome is based on major and minor clinical criteria initially described by Gurd (Table 1) ${ }^{7}$.

Table 1: Gurd's Criteria

\begin{tabular}{|c|c|}
\hline Major features & $\begin{array}{l}\text { Petechial rash } \\
\text { Respiratory symptoms plus bilateral signs with } \\
\text { positive radiographic changes } \\
\text { Cerebral signs unrelated to head injury }\end{array}$ \\
\hline Minor features & $\begin{array}{l}\text { Tachycardia } \\
\text { Pyrexia } \\
\text { Retinal fat or petechiae } \\
\text { Urinary fat globules or oligoanuria } \\
\text { Sudden drop in Hg-level } \\
\text { Sudden thrombocytopenia } \\
\text { High erythrocyte sedimentation rate } \\
\text { Fat globules in sputum }\end{array}$ \\
\hline
\end{tabular}

\section{Adapted from Talbot \& Schemitsch}

However, no universal FES definition exists. Gurd proposed FES could be diagnosed by one major criteria, four minor criteria, with the presence of fat macroglobulinemia ${ }^{7}$. Since several authors have adjusted the criteria with 2 major criteria, 1 major and 3 minor, 2 major and 2 minor, or 1 major and 2 minor being sufficient to establish a diagnosis of $\mathrm{FES}^{4}$. Computed tomography (CT) of the chest is helpful when the diagnosis is in question ${ }^{1}$. CT is especially helpful in differentiating pulmonary thromboembolism or pneumonia from the fat embolism. FES is associated with ground-glass opacities with septal lines in a geographic distribution and centrilobular nodules ${ }^{1}$ Magnetic resonance imaging of the brain is the imaging modality of choice to evaluate for emboli within the CNS when changes in mental status are present. MRI findings include multiple, nonconfluent, hyperdense lesions in a watershed distribution ${ }^{5}$. The degree of pulmonary and cerebral involvement is associated with disease severity ${ }^{1}$.

Treatment is aimed at providing respiratory support, adequate hydration, vasopressor support, and management of increased intracranial pressure as indicated by the clinical presentation. Corticosteroid use has been proposed to ameliorate the inflammatory cascade that results from fat emboli. However, their utility has yet to be supported by the literature ${ }^{8}$. Anticoagulation has not been shown to be effective ${ }^{5}$. 
Children who have Duchenne muscular dystrophy (DMD) or sickle cell anemia are at increased risk for FES. Our patient met FES criterion with one major criteria of respiratory symptoms and radiographic findings along with fever and tachycardia. Research is primarily limited to case reviews and a recent systematic review, but there are several proposed theories exist to explain the increased incidence in children with DMD $^{9-13}$. The increased adiposity of subcutaneous and muscular tissue increases the risk of translocation of fat globules into the circulation ${ }^{14}$. Similar to our patient, children with DMD are typically on chronic steroid use increase the adiposity of bone marrow and results in osteopenia ${ }^{15}$. Osteopenia, immobility and muscular weakness increases the likelihood of fractures as well as decreases the severity of injury required ${ }^{3}$. The increased adiposity also likely increases the burden of fat globules circulating which therefore increases morbidity and mortality. Given the poorer outcomes, clinicians need to be able to identify clinical symptoms early so that they can provide aggressive supportive care. Similar to our case, FES should be considered when encountering persistent tachycardia unresponsive to therapy in the setting of a recent fracture. Recognition of FES is necessary as the presenting of symptoms of FES could easily be confused with progress respiratory or cardiac issues experienced by children with DMD.

\section{Conclusion}

Patients with DMD are at increased risk to develop FES, following less significant trauma. In addition, FES may have severe outcomes if not recognized in a timely fashion and must be considered in the differential for DMD children with recent trauma, and acute onset of respiratory symptoms or altered mental status.

\section{References}

1. Newbigin K, Souza CA, Armstrong M, et al. Fat embolism syndrome Do the CT findings correlate with clinical course and severity of symptoms? A clinical-radiological study. European journal of radiology. 2016;85(2):422-427.
2. Lindeque BG, Schoeman HS, Dommisse GF, Boeyens MC, Vlok AL. Fat embolism and the fat embolism syndrome. A double-blind therapeutic study. The Journal of bone and joint surgery. British volume. 1987;69(1):128-131.

3. Stein PD, Yaekoub AY, Matta F, Kleerekoper M. Fat embolism syndrome. The American journal of the medical sciences. 2008;336(6):472-477.

4. Talbot M, Schemitsch EH. Fat embolism syndrome: history, definition, epidemiology. Injury. 2006;37 Suppl 4:S3-7.

5. Shaikh N. Emergency management of fat embolism syndrome. Journal of emergencies, trauma, and shock. 2009;2(1):29-33.

6. Mellor A, Soni N. Fat embolism. Anaesthesia. 2001;56(2):145-154.

7. Bulger EM, Smith DG, Maier RV, Jurkovich GJ. Fat embolism syndrome. A 10-year review. Archives of surgery (Chicago, Ill. : 1960). 1997;132(4):435-439.

8. Sen RK, Tripathy SK, Krishnan V. Role of corticosteroid as a prophylactic measure in fat embolism syndrome: a literature review. Musculoskeletal surgery. 2012;96(1):1-8.

9. McAdam LC, Rastogi A, Macleod K, Douglas Biggar W. Fat Embolism Syndrome following minor trauma in Duchenne muscular dystrophy. Neuromuscular disorders : NMD. 2012;22(12):1035-1039.

10. Feder D, Koch ME, Palmieri B, Fonseca FLA, Carvalho AAS. Fat embolism after fractures in Duchenne muscular dystrophy: an underdiagnosed complication? A systematic review. Therapeutics and clinical risk management. 2017;13:1357-1361.

11. Bugnitz CJ, Cripe LH, Lo WD, Flanigan KM. Recurrent Fat Embolic Strokes in a Patient With Duchenne Muscular Dystrophy With Long Bone Fractures and a Patent Foramen Ovale. Pediatric neurology. 2016;63:76-79.

12. Stein L, Herold R, Austin A, Beer W. Fat Emboli Syndrome in a Child with Duchenne Muscular Dystrophy After Minor Trauma. The Journal of emergency medicine. 2016;50(5):e223-226.

13. Medeiros MO, Behrend C, King W, Sanders J, Kissel J, Ciafaloni E. Fat embolism syndrome in patients with Duchenne muscular dystrophy. Neurology. 2013;80(14):1350-1352.

14. Torriani M, Townsend E, Thomas BJ, Bredella MA, Ghomi RH, Tseng BS. Lower leg muscle involvement in Duchenne muscular dystrophy: an MR imaging and spectroscopy study. Skeletal radiology. 2012;41(4):437-445

15. Kerachian MA, Seguin C, Harvey EJ. Glucocorticoids in osteonecrosis of the femoral head: a new understanding of the mechanisms of action. The Journal of steroid biochemistry and molecular biology. 2009;114(3-5):121-128. 